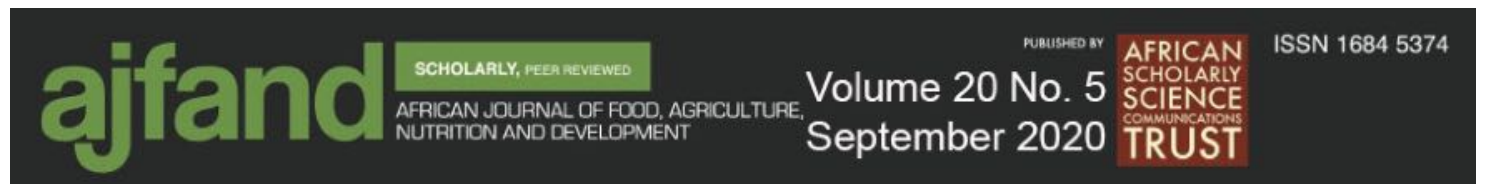

Afr. J. Food Agric. Nutr. Dev. 2020; 20(5): 16420-16446 $\quad$ https://doi.org/10.18697/ajfand.93.19460

\title{
ASSESSMENT OF AFLATOXIN AND FUMONISIN CONTAMINATION LEVELS IN MAIZE AND MYCOTOXINS AWARENESS AND RISK FACTORS IN RWANDA
}

Niyibituronsa $M^{1 *}$, Mukantwali $C^{1}$, Nzamwita $M^{1}$, Hagenimana $G^{1}$, Niyoyita $S^{1}$, Niyonshima $A^{1}$, Hakizimana $C^{1}$, Ndilu $L^{1}$, Nyirahanganyamunsi $G^{1}$, Nkurunziza $\mathbf{E}^{\mathbf{1}}$, Sendegeya $\mathbf{P}^{\mathbf{1}}$, Niyonteze $\mathbf{G}^{\mathbf{1}}$, Muhutu $\mathrm{JC}^{\mathbf{1}}$, Shingiro $\mathbf{J B}^{\mathbf{1}}$, Umuhire $\mathbf{J}^{\mathbf{1}}$, Nyirahorana $\mathbf{C}^{\mathbf{1}}$, Ingabire $\mathbf{A C}^{\mathbf{1}}$, Nyiranshuti $\mathrm{A}^{\mathbf{1}}$, Sibomana $\mathbf{E}^{\mathbf{1}}$, Usabyembabazi $\mathbf{M}^{\mathbf{2}}$, Munganyinka $\mathrm{E}^{1}$, Gasana $\mathrm{AP}^{1}$, Kamaraba $\mathbf{I}^{1}$, Izamuhaye $\mathrm{JC}^{1}$ Nkundanyirazo $^{2}$, Ngaboyisonga $C^{1}$, Bucagu $C^{1}$ and $P$ Karangwa ${ }^{1}$

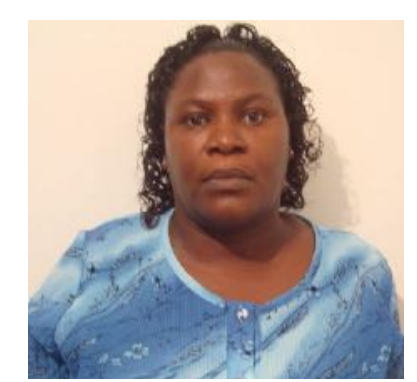

Marguerite Niyibituronsa

*Corresponding author email: niyibituronsam@gmail.com

${ }^{1}$ Rwanda Agriculture and Animal Resources Development Board (RAB), Rwanda, P.O. Box 5016 Kigali, Rwanda

${ }^{2}$ Post-Harvest and Agribusiness Support Project (PASP), Rwanda 


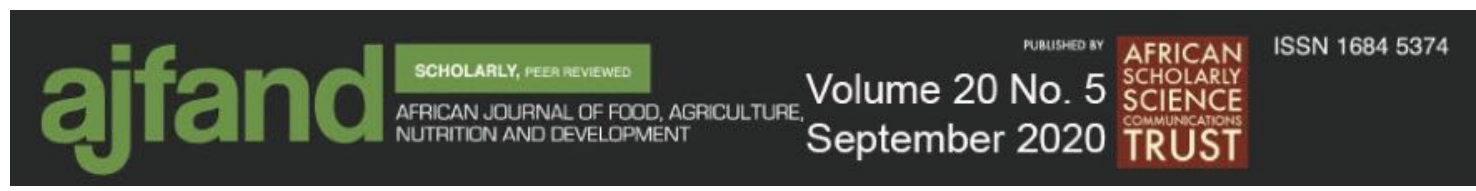

\begin{abstract}
Mycotoxins are secondary metabolites of fungi that are toxic to humans and animals when consumed in contaminated food and feed. The Rwandan climate conditions like steady temperature and sufficient rainfall favor the growth of fungi leading to high probability of mycotoxins contamination. Mycotoxins get into maize throughout the value chain from the field to processed products. Maize is promoted in Rwanda under the Crop Intensification Program (CIP), for nutrition and food security. The aim of the study was to evaluate mycotoxins (Aflatoxin and fumonisin) levels in maize and assess awareness and factors associated with mycotoxin contamination in Rwanda. Maize samples $(227 \mathrm{~kg})$ from season B 2019 were collected in 15 Districts in five provinces of Rwanda after an interview with a representative of the household or cooperative using a structured questionnaire. The samples were analyzed for aflatoxin and fumonisin using Reveal $\mathrm{Q}^{+}$and AccuScan Gold Reader. From the interview, most of the respondents were not aware about aflatoxin $(59.7 \%)$ and $99 \%$ did not know the effect of mycotoxins on human health. The average of aflatoxin contamination in surveyed districts was $6.69 \pm 13 \mu \mathrm{g} / \mathrm{kg}$. In general, $90.4 \%$ of samples scored below the limit of aflatoxin level regulated in East Africa/Kenya regulation standards $(10 \mu \mathrm{g} / \mathrm{kg})$. The levels of aflatoxin ranged between 0 and $100.9 \mu \mathrm{g} / \mathrm{kg}$. The means aflatoxin levels within districts ranged between $1.36 \pm 0.5 \mu \mathrm{g} / \mathrm{kg}$ and $13.75 \pm 25 \mu \mathrm{g} / \mathrm{kg}$. Among $9.6 \%$ of the samples containing aflatoxins above the EU and Kenyan regulations standard limit, 5.7 \% were above the US standards of $20 \mu \mathrm{g} / \mathrm{kg}$. Within clusters, the level of aflatoxin more than $10 \mu \mathrm{g} / \mathrm{kg}$ was $5 \%, 7 \%$ and $18 \%$ for stores, household and market samples, respectively. From the study, as mechanical damage of grains, moisture content of grains and the temperature of the store house increased, Aflatoxin level also increased. Fumonisin analyzed in maize ranged from 0 to $2.3 \mu \mathrm{g} / \mathrm{g}$ and only one sample from market showed a slightly higher level of fumonisin than the EU and US limit of $2 \mu \mathrm{g} / \mathrm{g}$. More effort for aflatoxin mitigation is needed at the market level. Farmers need to be aware and taught how they can improve their agricultural system and more knowledge on mycotoxin control is needed. The results point to appropriate measures to recommend for control of mycotoxins in Rwanda and awareness creation.
\end{abstract}

Key words: AccuScan, Aflatoxin, Fumonisin, Fungal, Maize, Mycotoxins, Reveal Q+, Rwanda 


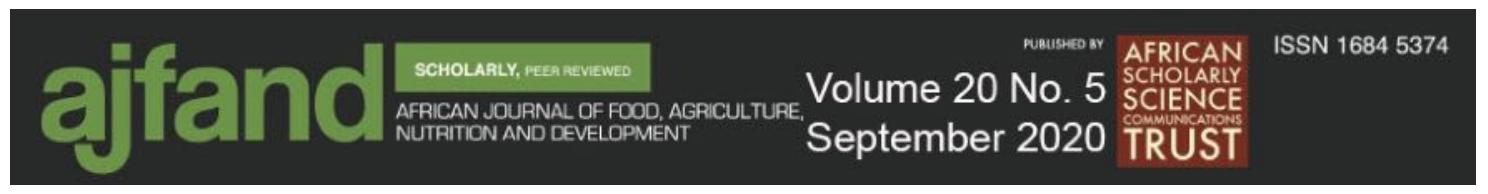

\section{INTRODUCTION}

Agriculture is one of the sectors that support the economy of Rwanda as it contributes about $31 \%$ to the Gross Domestic Product (GDP) [1]. The agricultural household survey report shows that the engagement of households in agriculture in Rwanda is estimated at $80.2 \%$ of the total households [2]. Moreover, the predictions show that agriculture will still contribute to the growth of Rwandan economy growth through the National Strategy for Transformation program [3]. Among priority crops promoted under the Crop Intensification Program (CIP), maize is promoted for nutrition and food security, making it as one of the staple crops in Rwanda. Besides the effort to boost agriculture for economic growth, the Rwandan climate conditions favor the growth of fungi, hence, leading to high probability of mycotoxins contamination. Mycotoxins are toxic secondary metabolites produced by several fungi that are harmful to humans and animals that consume them $[4,5]$. Mycotoxins get into maize at many points along the value chain from the field to processed products [5]. The risk of mycotoxin contamination is associated with climate conditions, pre- and post-harvest handling and storage practices of maize. The warm climatic conditions of Rwanda favor the growth of fungi responsible for mycotoxin production Milani [6] reported the optimum temperature for aflatoxins and fumonisin production of $33^{\circ} \mathrm{C}$ and $15-30^{\circ} \mathrm{C}$ respectively. Fungi contamination of maize occurs from pre-harvest phase when maize is wounded by insects and birds in the field, to post-harvest operations of handling, drying, threshing, transport and storage when environmental conditions are unsuitable. Warm temperatures and increased moisture are key among the environmental conditions that favor the growth of fungi after harvest. Hence, the control of environmental conditions where maize is grown, handled and stored is significant to minimize the risk of contamination [6]. Moreover, mycotoxins are stable to post-harvest and processing practices [4,5], making their control problematic.

Different fungal strains such as Aspergillus, Fusarium and Penicillium produce mycotoxins [4]. The most common mycotoxins are aflatoxins, fumonisins, zearalenone, deoxynivalenol and ochratoxins [4,7]. This study focused on aflatoxins (AF) and fumonisins (FB), which accumulate in food commodities handled and stored under favorable conditions [8]. Aflatoxins are produced by Aspergillus fungal strains and are considered to be highly carcinogenic [9]. A. flavus and A. parasiticus strains are common in maize [10]. Fumonisins are also common in maize, produced by mainly Fusarium verticillioides and $F$. proliferatum. Fumonisins B1 is abundant in maize flour. Fumonisins have been reported as abundant types of mycotoxins in samples collected in sub-Saharan African countries [11]. Aflatoxins and fumonisins cause health hazards including cancer and stunting in children [12], leading to total rejection of contaminated food at national, regional and international markets.

In line with human health protection and fair-trade promotion, standards and acceptable levels of mycotoxins are set to regulate the occurrence of mycotoxins in food and feed. In the East African food standards, the set maximum levels are $10 \mathrm{ppb}$ for total Aflatoxin and $0.05 \mathrm{ppm}$ for Fumonisin feeds or food [13]. As a result of improper post-harvest handling, farmers have been experiencing rejection in compliance with regional and international standards of their produce due to elevated levels of mycotoxins [13]. 


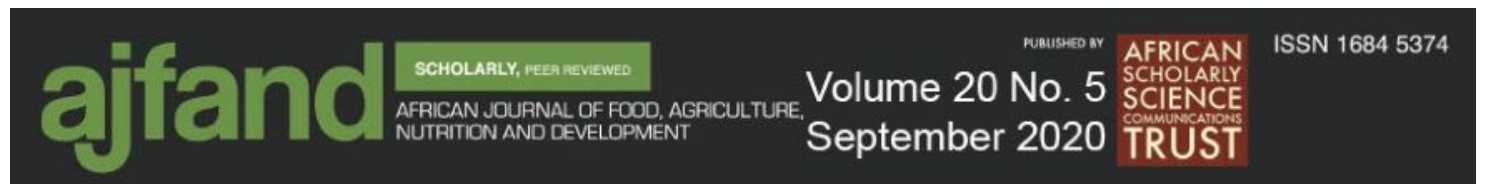

Nevertheless, maize is a significant staple crop in Rwanda, yet there is still limited information on mycotoxin prevalence in maize value chain. A limited number of studies reported the occurrence of mycotoxins at the level of sellers. Hence, this study was conducted to assess the prevalence of major mycotoxins including aflatoxins and fumonisins along the post-harvest chain of maize, from farmer to market. Furthermore, this study identified mycotoxin risk factors from harvest to market of maize. Mycotoxin contamination is worsened by limited information and knowledge among the value chain actors. In a study conducted by Magembe et al. [14] in Tanzania, $48.6 \%$ of respondents reported that they have skills to detect rotten maize [14]. However, 97.2\% have not heard about mycotoxins. Similarly, Umereweneza et al. [15] reported limited awareness on mycotoxins in Rwanda [15]. Hence, the findings of this study provide supporting information for policy makers and relevant stakeholders to develop strategies and appropriate measures for awareness and mitigation on mycotoxin contamination.

\section{MATERIALS AND METHODS}

\section{Sampling}

\section{Sampling sites}

The study was conducted in five provinces of Rwanda, specifically in Districts suitable for maize production, including where Post- Harvest and Agribusiness Support Project (PASP) carried out their activities. A multistage method was used to select, randomly, three districts per province, namely: Kirehe, Gatsibo and Nyagatare in East; Nyarugenge, Kicukiro and Gasabo in Kigali; Gakenke, Musanze and Gicumbi in North; Nyanza, Muhanga and Kamonyi in South; and Rusizi, Nyabihu and Rubavu in Western Province. Only five Districts were not under the PASP project, namely: Nyarugenge, Kicukiro, Gasabo, Gicumbi and Rusizi. Two hundred twenty-seven samples (227 Kg) of dried maize grains from season B 2019 were collected, for Aflatoxin and fumonisin analysis, in selected Districts as mapped in the Figure 1. Samples were collected from different clusters, namely: households, warehouses, stores, markets and processors, after an interview with the representative using a structured questionnaire. The information was recorded for post-harvest handling and Aflatoxin awareness. Geospatial data were recorded using Global Positioning System (GPS). 

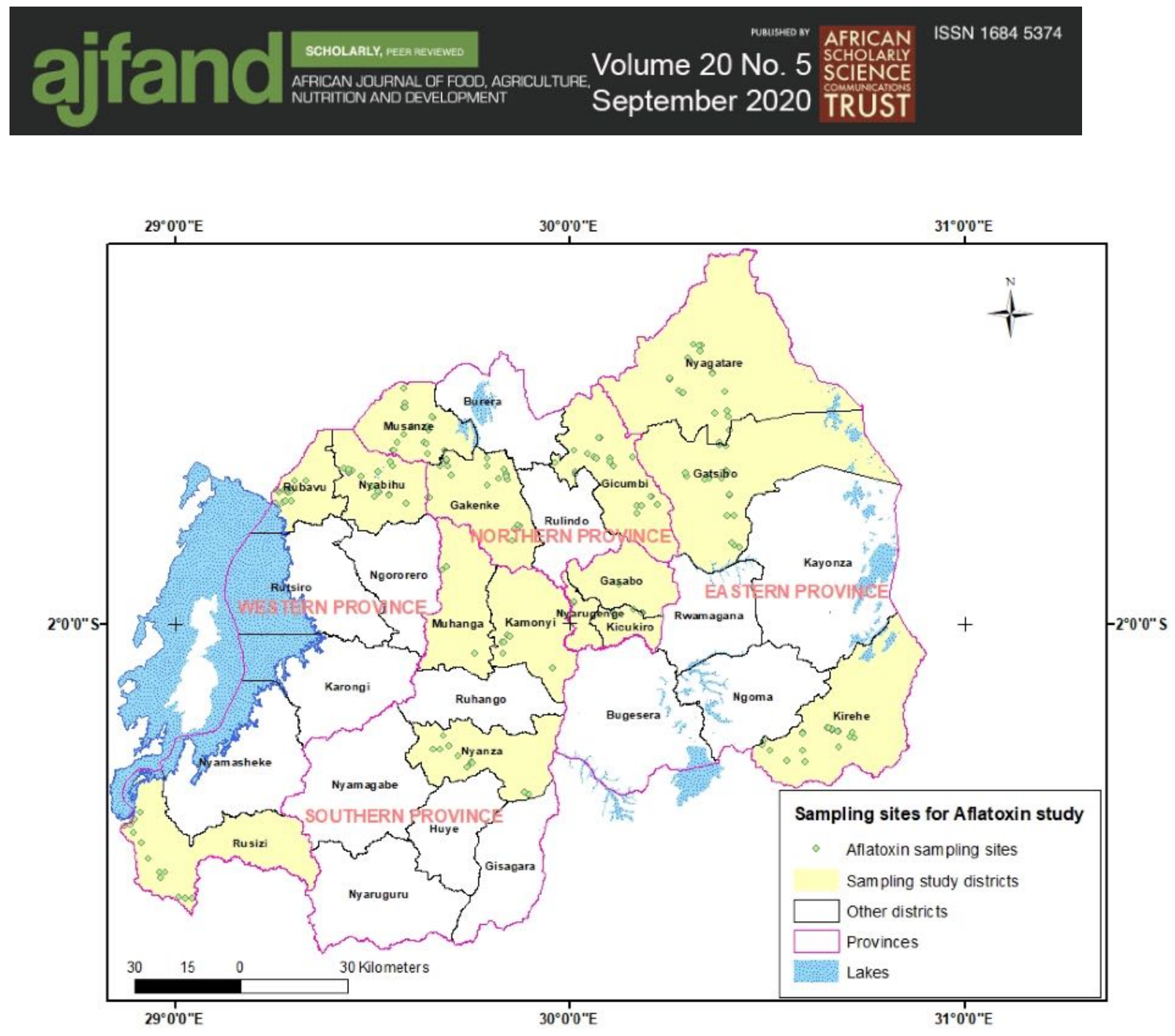

Figure 1: Sampling sites for Aflatoxin study in five provinces of Rwanda

\section{Sampling methods}

From each respondent, a sample (approximately $1 \mathrm{~kg}$ ) was collected. The sample was taken in different parts of each bag using a grain Trier and the aggregate sample was mixed, then $1 \mathrm{~kg}$ was collected as a representative sample, according to Whitaker guideline for sampling food for mycotoxins analysis [16]. One $\mathrm{kg}$ of the sample was packed in a paper bag (container made of paper) and labeled with the following information: day and month / crop/source/ district /code. The total samples collected from different clusters were $227 \mathrm{~kg}$ of maize. The samples were transported in polyethylene bags to the cold room at $\left(+4^{\circ} \mathrm{C}\right)$ to avoid the contamination accumulation before laboratory analysis at Rwanda Agriculture and Animal Resources Development Board (RAB) Rubona station, Huye District.

\section{Sample preparation}

Maize samples were collected exhaustively from country-wide survey in agro-ecological maize zones of Rwanda and under PASP project. Maize samples $(227 \mathrm{~kg})$ collected from the households $(105 \mathrm{~kg})$, market $(56 \mathrm{~kg})$, stores $(58 \mathrm{~kg})$, warehouses $(4 \mathrm{~kg})$ and processors $(4 \mathrm{~kg})$ were ground using a milling machine until a fine powder was obtained. A sub-sample of $100 \mathrm{~g}$, representative for laboratory analysis, was collected in sample 


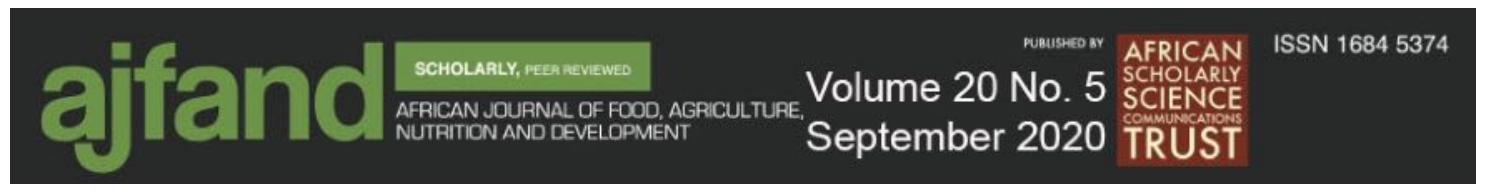

plastic bags and kept in cold room at $+4^{\circ} \mathrm{C}$. These samples were prepared by weighing $10 \mathrm{~g}$ mixed with $65 \%$ ethanol, and shook vigorously for 3 minutes to get sample extract ready for determination of aflatoxin and fumonisin contamination.

\section{Determination of Aflatoxin contamination in maize}

Following manufacturer instructions, five hundred microliters $(500 \mu 1)$ of sample diluent were added into a well labeled red dilution cup followed by addition of $100 \mu \mathrm{l}$ of sample extract into the red sample dilution cup containing sample diluent and mixed by pipetting up and down for 5 times. One hundred microliters $(100 \mu 1)$ of diluted sample extract was transferred into a new clear sample cup. The Reveal Q plus test strip was placed with the sample end down in the sample cup for 6 minutes. The measurement was done using a calibrated AccuScan Gold Reader. The limit of detection was $2 \mathrm{ppb}$ and the range of quantification was between 2 and 100ppb. Samples above 100ppb were diluted by repeating the test procedure. Neogen products used were certified and validated according to ISO 9001 [17].

\section{Determination of Fumonisin contamination in maize}

The test was done according to the manufacturer instructions as follows: Samples extract $(100 \mu \mathrm{l})$ was added to the red cups and $200 \mu \mathrm{l}$ of diluents, and then mixed by pipetting up and down 5 times. The diluted sample extracts $(100 \mu l)$ was transferred into a clear sample cup. A new Reveal Q+ for Fumonisin test strip was placed into the sample cup for 6 minutes. The strip was removed from the sample and read immediately using AccuScan Gold Reader [18].

\section{Data analysis}

Data were analyzed using GenStat 14 ed. and IBM statistics SPSS 22 software, and the analysis of variance was used to test the significance of difference between variables at 95\% level of confidence. Means were separated using least significance difference (LSD) post hoc tests. A T-test was used to analyze the difference between Districts under PASP intervention and those which did not benefit.

\section{RESULTS AND DISCUSSION}

\section{SOCIOECONOMIC CHARACTERISTICS OF RESPONDENTS}

The socioeconomic characteristics indicated that $55 \%$ of respondents were men while $45 \%$ were women. The average age of respondents was 46 years with a minimum and a maximum of 23 and 84 years, respectively. The average age tends to indicate that most of the respondents were adults. Majority of the respondents had primary education $(69.67 \%)$. The proportion of those who had no formal education was $21.1 \%$, while those who had vocational or secondary education were $8.53 \%$ and $9.53 \%$, respectively. The remaining respondents had university education $(2.84 \%)$.

\section{Awareness of respondents on mycotoxins}

According to the results of this study, the awareness of aflatoxin was low. Most of the respondents were not aware about aflatoxin (59.7\%) while $40.3 \%$ had heard about it. Among the $40.3 \%$ who are aware of aflatoxin, $36.8 \%$ knew its source and $0.51 \%$ of respondents knew the effect of aflatoxin. Moreover, the study revealed that many buyers 


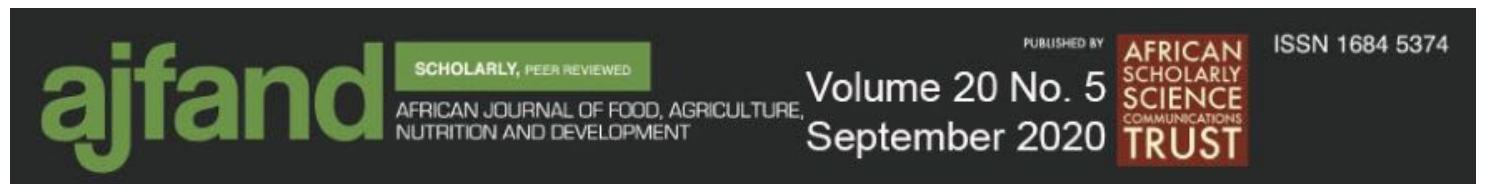

did not respect the standards of safety regarding aflatoxin in maize (95.97\%). Only 4.32 $\%$ know about those standards. Some of them (4.03\%) have some knowledge about the limit of aflatoxin in maize while $95.97 \%$ do not have information. Older participants were more likely to know about aflatoxin than younger participants. This could possibly be because the older farmers may have learnt about aflatoxin. Johnson et al. [19] reported that among 648 farmers surveyed in Nigeria, 88\% heard about the negative impact of aflatoxin on child growth, and $92 \%$ believed aflatoxin is bad for the health of their families [19].

\section{Awareness of respondents on causes of aflatoxin}

Molds, those microscopic fungi, were identified by respondents $(34.5 \%)$ as primarily the cause of aflatoxin. According to the interview during the survey, farmers $(35 \%) \mathrm{knew}$ that aflatoxin was caused by mold, information which they got from the agronomists of local administrative entities and the farmer promoters from village level. On the other hand, high humidity $(8 \%)$, poor storage $(6.9 \%)$, weevil $(4.6 \%)$, and others $(12.6 \%)$ including heavy rain and rodents were known causes of aflatoxin (Figure 2). Sahil et al. [20] reported that warm temperature, high humidity, high moisture either in the growing fields, transportation conditions or storage conditions; infestation by insects and other micro-organisms can expose commodities to colonization by toxigenic fungi producing mycotoxins [20].

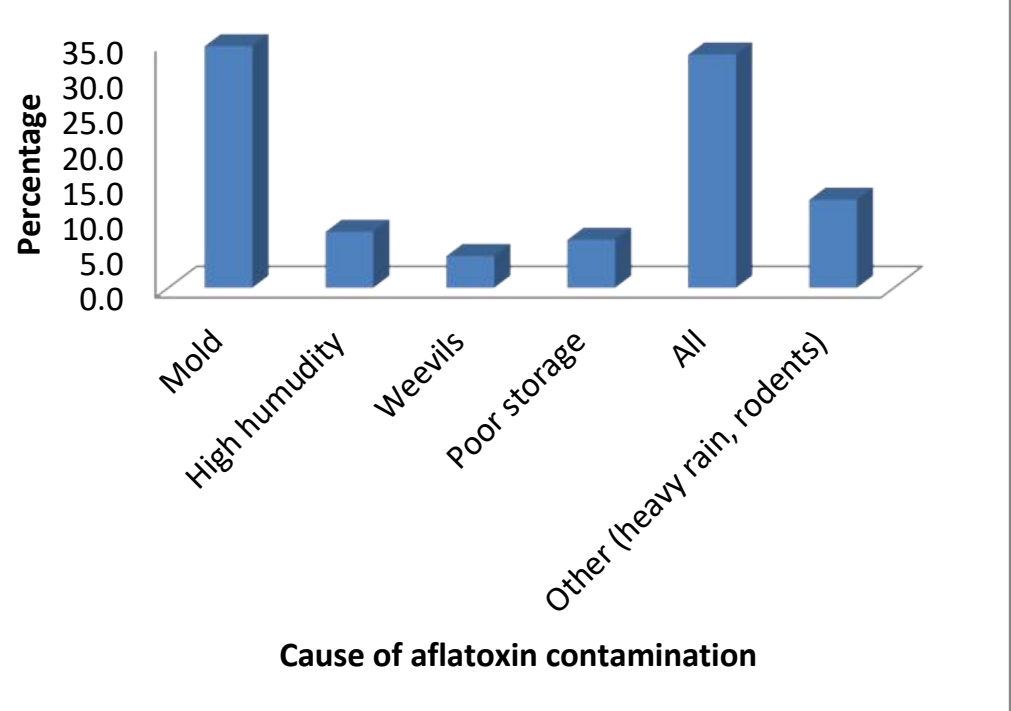

Figure 2: Knowledge of farmers on causes of aflatoxin contamination

\section{Maize ownership}

Maize samples were collected from different category of maize producers. A large number of maize samples were taken from smallholder farmers (94.63\%), while $1.95 \%$, $1.95 \%$ and $2.84 \%$ came from large scale maize growing farmers' cooperatives, companies and markets. respectively. The Rwandan agricultural policies focus on changing the farmers from subsistence to market orientation [21]. One strategy to reach the goal is to form the cooperatives. The ownership does not only influence in determination on the use of the production but also in the postharvest management [22]. 


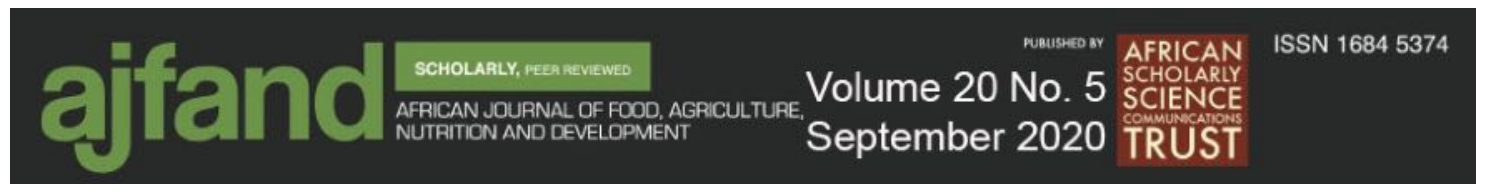

\section{Postharvest handling of maize}

The study finds that the majority of farmers $(73.99 \%)$ harvested their maize during the dry season (June-August), while $26.01 \%$ of farmers harvested during the rainy season (February, March, April). The average of drying duration was 27 days with a minimum of 2 days and a maximum of 40 days. Most of the collected samples were grains $(90.65$ $\%)$. The remaining samples were cobs $(1.79 \%)$ and flour $(1.40 \%)$. The average of the moisture content of samples was 13.91 with a minimum of 3.5 and a maximum of 22.5 . The insect damage in one kilogram of grain sample mean was estimated at $4.24 \%$ with a minimum of zero and a maximum of $52.1 \%$, whereas the mean for mechanical damage of grain samples was estimated at $1.13 \%$ with a minimum of zero and a maximum of $2.57 \%$. The average temperature of sample collected was $27.13{ }^{\circ} \mathrm{C}$ with a minimum of $18.9^{\circ} \mathrm{C}$ and a maximum of $37^{\circ} \mathrm{C}$ (Table 1). These findings correlate with the findings of USAID findings of 2012 in Rwanda [23]. The drying duration after maize harvest influences production of aflatoxin because of $A$. flavus infects at specific moisture and humidity levels [24].

\section{Sorting of the grains and criteria}

Few farmers do the sorting (24.94\%). Among them, $24.1 \%$ do the sorting while in the field, $24.1 \%$ do the sorting while drying and $33.9 \%$ do the sorting when the grains are in storage. From this result, the high line of sorting criteria of different variables among sampled farmers was immature maize with mold $(51.2 \%)$ followed by immature maize $(19.3 \%)$. Other sorting criteria were: the presence of weevils in maize grain, maize damaged by birds and the rotten ones. Majority of farmers $(58 \%)$ do the sorting by separating the good grains from bad ones and for $18.1 \%$ of farmers, the bad grains were fed to animals while $13 \%$ of farmers rejected the bad grains. The sorting should be done for both market orientation and household nutrition [25]. Research conducted by Kumar et al.[26] indicated that the sorting techniques could reduce the contamination of aflatoxin from $80 \%$ to $40 \%$ [26].

\section{Drying facilities and challenges}

Farmers were asked the types of drying facilities they used to dry maize grains. The use of sheeting was the most predominant facility $(51.1 \%)$ while $32.02 \%$ suspended the maize cobs in their homes. The methods of hanging maize cobs and use of sheeting were also the practices mentioned by farmers in 2012 [20].

According to results, the big issues of maize drying were: lack of drying materials (36.6 $\%)$, use of inappropriate material $(17.6 \%)$ and rain $(16.9 \%)$ during the drying period (Figure 3). 

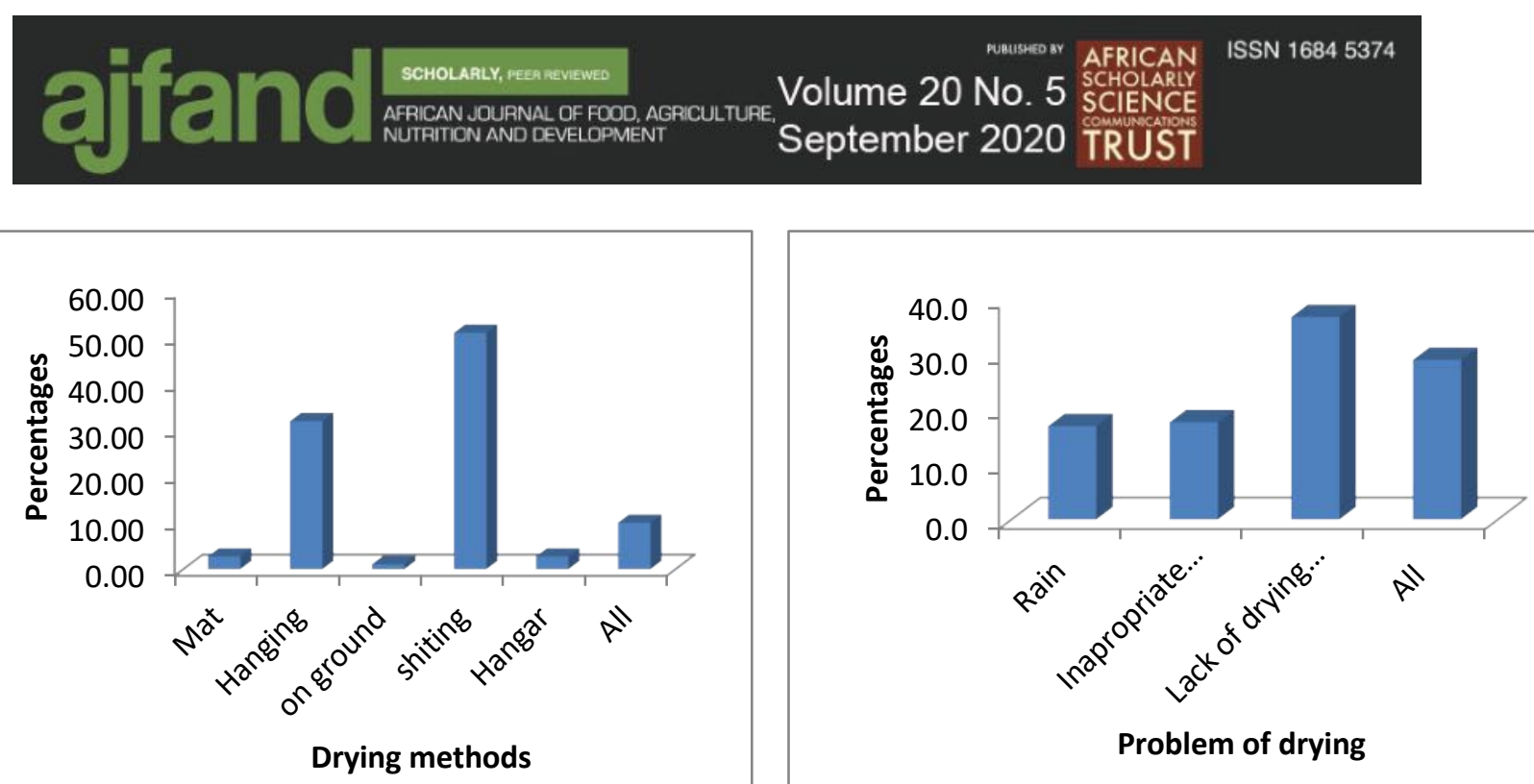

Figure 3: Drying facilities and Challenges

With an aim of reaching and maintaining the moisture content recommended [27], many farmers did not access the drying machine [28] and most famers dried naturally the maize in sun, thus increasing the drying length and affecting its quality; precisely, the fungi tends to grow after the harvest and during the rain [29]. In coping with the humid rainy climate, the farmers utilize inappropriate methods [30]. Fig 3 shows the different challenges faced by the farmers. Respondents pointed out that the lack of drying material affects the quality and quantity of the production. Harvesting maize during the rainy season is challenging as the farmers rely on the sun for drying. The inappropriate methods used such as hanging the maize cobs under house roofs are causing increased moisture content within the grain [29].

\section{Test of dried maize}

Many of farmers tested the dried maize with teeth (the grain is dried when the teeth do not enter in the grain) $(37.5 \%)$, followed by observation $(29.2 \%)$ and both teeth and observation $(20.8 \%)$. Few numbers $(6.8 \%)$ have used moisture meter and the remaining farmers $(5.7 \%)$ used teeth, observation, and taping together.

Under humid and warm conditions, harvested grains are susceptible to fungi, and, therefore, drying is among the techniques to inhibit the molding and rapid deterioration of the grain. Drying to the recommended moisture level is not economical for famers [27] due to lack of access to equipment for measuring the moisture content and drying [31]. A few recently developed instruments show promise but there is little research on how small-scale farms and co-operatives in developing countries can achieve a safe standard for their dried foods. Of these, two potential methods, equilibrium relative humidity and infrared imaging, were identified as promising techniques, but further research and development would be needed to make them appropriate for these conditions [32]. As earlier stated, many farmers use the crude methods. The crude methods do not ensure quality of product.

\section{Types of holding materials}

The results showed that many farmers used local materials, namely, tree trunk/the simple timbers and pallets as holding materials. It represented $28.1 \%$ and 26.7 , respectively, 


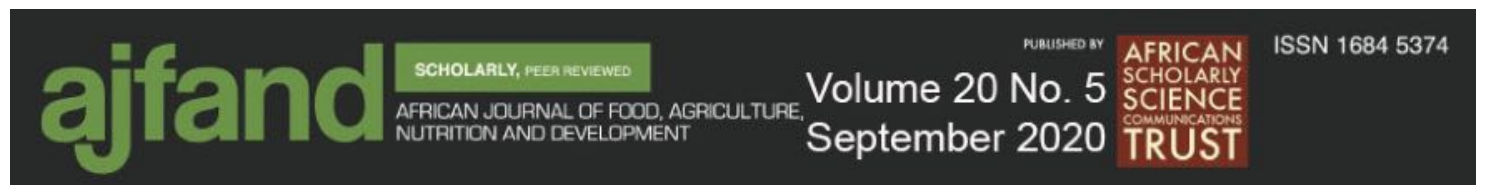

and $25.3 \%$ of respondents dried on the ground, which can be a source of contamination (Figure 4). Stacking for easy management, the bag should be placed on dunnage to avoid the moisture from the ground getting into the grain and ensure safety [33]. Unfortunately, the cross contamination can occur during storage when the bags are kept on the ground [26].

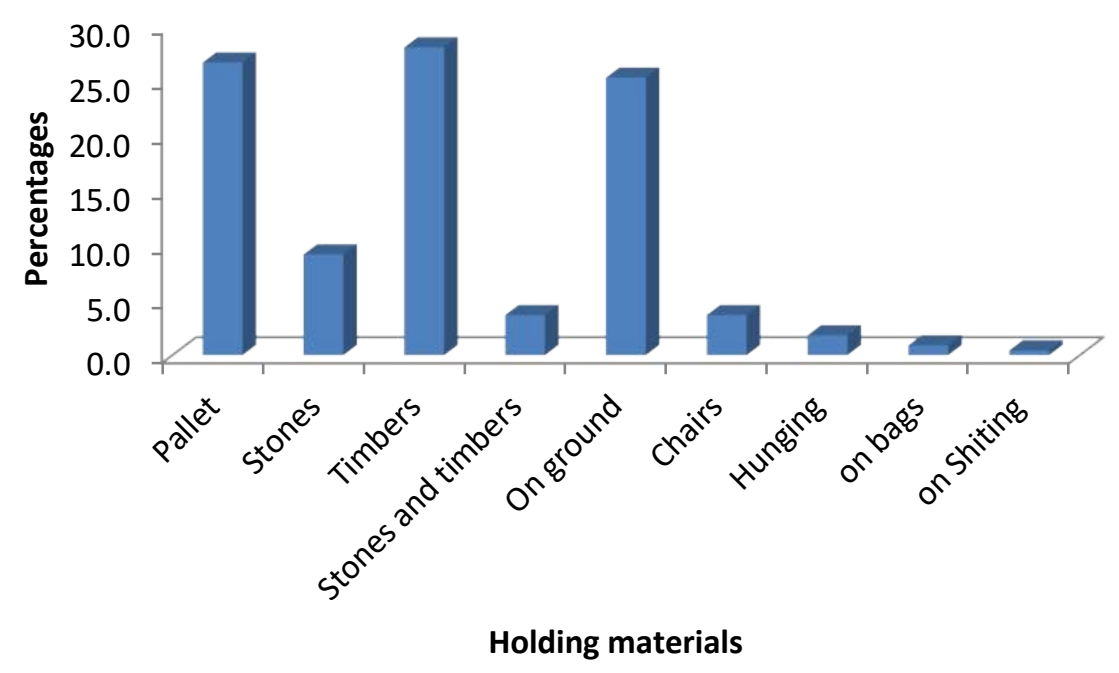

Figure 4: Different holding material in the stores

\section{Use of maize}

Intended use of maize in sampled sites revealed that maize was produced for the market $(41.3 \%)$, then $27.5 \%$ was for home consumption, $5.6 \%$ for seeds, $2.04 \%$ for animal feeds and around $1,53 \%$ maize was for processing (Figure 5). This concurs with other published works reporting that the smallholder farmers produce maize to consume and to sell at the local market [25]. The consumption of mycotoxin-contaminated commodities is related to several acute and chronic diseases in humans and animals. Recent examples of acute aflatoxicosis were in Kenya where the consumption of mouldy maize contaminated with aflatoxin resulted in $100+$ children dying and $400+$ hospitalized [34]. 

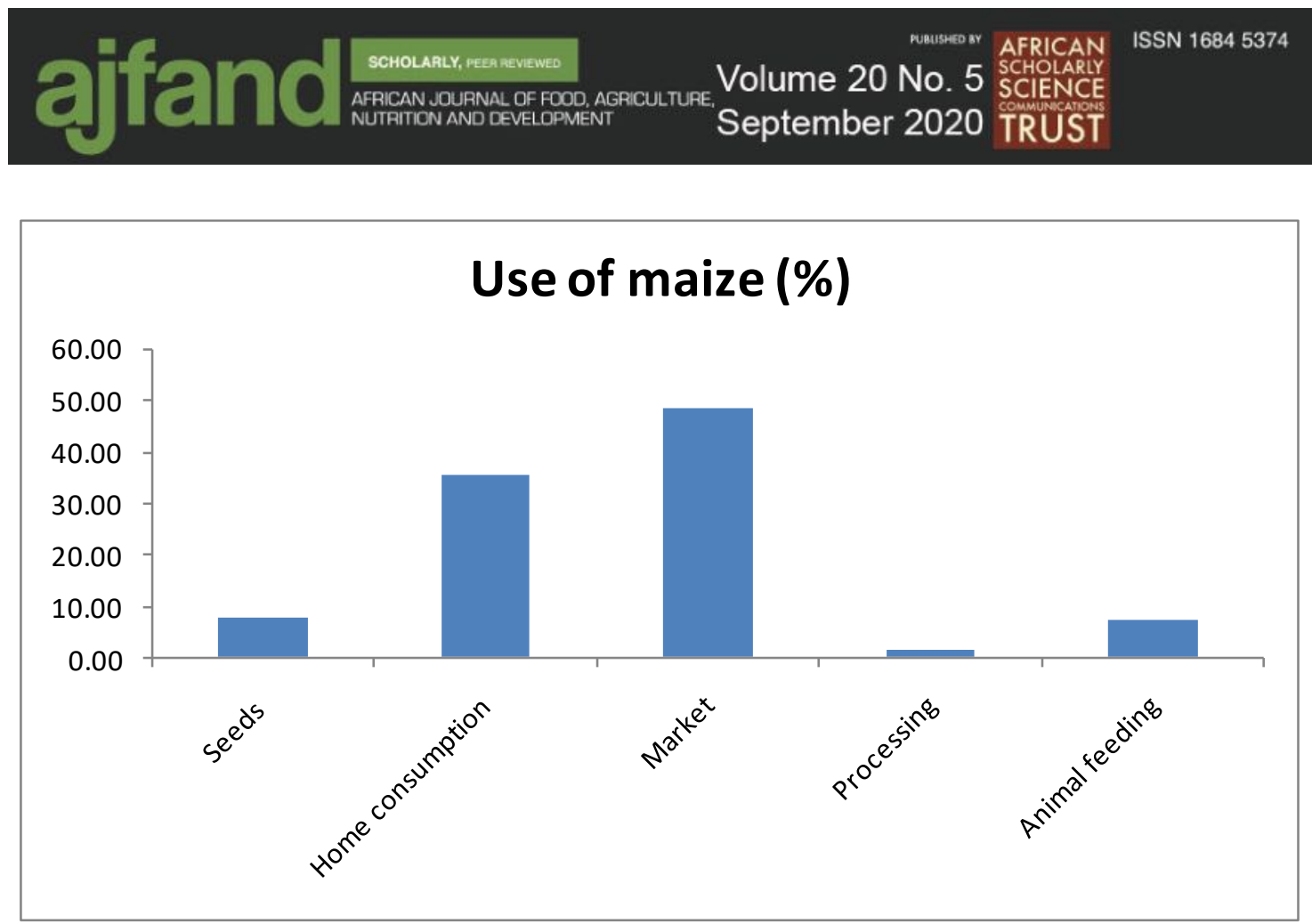

Figure 5: Intended use of maize

Therefore, worldwide, some research revealed that the mycotoxins are harmful toxins produced by moulds. Some of them, like aflatoxins and fumonisins are associated with certain cancers in humans; they also have a variety of negative impacts on animal health and productivity. Thus, the share intended for human consumption and those intended for use as animal feeds must be identified and focused on [35].

\section{Storage conditions}

The study results (Table 2) revealed that the average days of maize harvested to be stored were between 43 and 90 days. The poor storage conditions were observed for $49.28 \%$ of respondents. The storage was not allowing easy inspection $(56.73 \%)$, even if the stores were ventilated $(62.96 \%)$. Some of the respondents who had completely covered the insects present in the store represented a good percentage (43.19\%). Aspergillus flavus can infect maize in warm climates at pre-harvest stages, during crop growth and harvesting, and at postharvest during storage, transport and processing. Increase in aflatoxin content can occur if the phases of grain drying and storage are poorly managed [36].

\section{Chemical use in store}

Majority of respondents do not use chemicals for insect control in storage (84\%). Malathion is the most used chemical (5\%). Other chemicals used are Aluminium phosphate, Cleoline, DDT, Fumigation tablets, Rocket, and Supers canner at $11 \%$. The effects of the three fungicide treatments on mycelium growth were shown in previous studies where most of the fungicides reduced growth of the flavus strains [37].

\section{Maize store materials}

Storage is an important factor for conservation of farm products. The storage, especially of grains, requires housing with appropriate materials and well designed. This study revealed that materials used to construct the storage depended on the design and means 


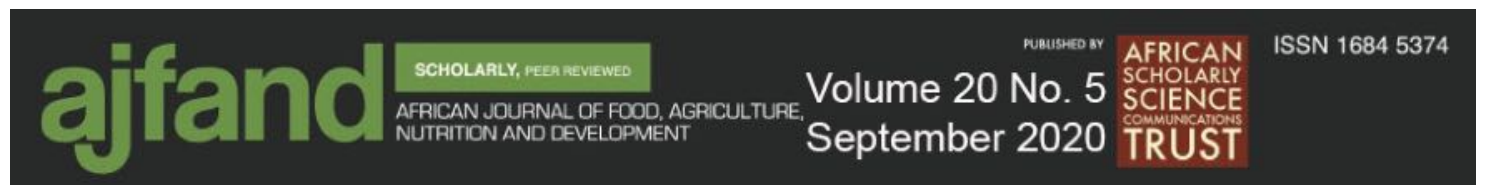

of farmers, where bricks adopted represented $21.79 \%$, and $30.73 \%$ were constructed with bricks and $28.21 \%$ with cement for the walls. For making the floor, the study showed that cement and mud were the most used for constructing the floor of store building, where cement represented $77.52 \%$ and $18.35 \%$ mud, while iron sheet was used by $87.44 \%$ to make roof (Table 3). Sumner and Lee in their article showed that the importance of storing grains required keeping moisture in stored grain below 12-13 percent to stop the development of aflatoxin, and to keep insect activity to a minimum to limit insect growth [38]. Therefore, inappropriate wall and roofing materials influenced the spoilage of grains during the storage. Befikadu [39] reported that inside the shelter, the products should be piled in boxes or on shelves or racks along the wall, in such a way that air can move freely between them and ensure regular inspection of stored products [39].

\section{Grain damage}

Respondents reacted also on the presence of weevils, birds and rodents in maize fields, during drying and in the stores. The presence of weevils was reported by $47.78 \%$ of respondents in the field, $54.95 \%$ during drying and $64.58 \%$ in storage. Rodents in the fields were stated by $45.3 \%$ of respondents, $48.9 \%$ during drying and $63.4 \%$ in storage. The presence of birds in the field was reported by $68.68 \%$ of respondents, $25.84 \%$ during drying and less present in storage $(5.88 \%)$.

This research refers to the study done by Summer and Lee [38] that the exposure to mycotoxins can also be due to insect damage to maize cobs. Insects can either act as vector of fungal pathogens by transferring the fungi or exposing the cob to infection from the atmosphere. Insect damage is of most important concern for Fusarium spp. mycotoxins such as fumonisin. However, grain damage can be minimized by good agricultural practices including harvesting, threshing and handling, and appropriate storage [39].

\section{Presence of molds}

The information on the level of molds was collected during the survey in different stages of maize from farm to final products. This was to determine the stage at which maize is most affected by molds. From the study, respondents observed molds at field level $(56.90 \%), 51.19 \%$ during drying and $38.25 \%$ in storage.

This means that the highest level of moulds occurs at field and drying levels than during storage. Sumner and Lee [38] reported that Aspergillus flavus as a common fungus found in soil and debris, occurs frequently in nature particularly as airborne spores, and can also be found on most grains in the field as well as in storage [38].

\section{Aflatoxin contamination levels in different districts surveyed}

The concentration of total aflatoxin in samples collected is summarized in Table 4. A total of 227 samples were collected in 15 districts of Rwanda and the levels of aflatoxin were evaluated. The levels of aflatoxin ranged between 0 and $100.9 \mu \mathrm{g} / \mathrm{kg}$. The means of aflatoxin levels within districts ranged between $1.36 \pm 0.5 \mu \mathrm{g} / \mathrm{kg}$ and $13.75 \pm 25 \mu \mathrm{g} / \mathrm{kg}$. Among all 15 districts surveyed, Rusizi district had the highest mean aflatoxin level $(13.75 \mu \mathrm{g} / \mathrm{kg})$ followed by Gatsibo $(10.14 \mu \mathrm{g} / \mathrm{kg})$. Those regions are known to have high 


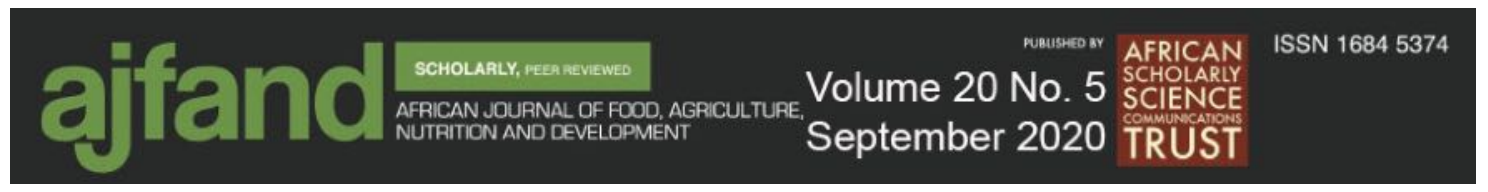

temperatures compared to others. The lowest mean aflatoxin level was observed in Kirehe district $(1.36 \mu \mathrm{g} / \mathrm{kg})$. The average of aflatoxin contamination in surveyed districts was $6.69 \pm 13 \mu \mathrm{g} / \mathrm{kg}$. The difference was not significant between Districts $(\mathrm{P}>0.05)$. Compared to the studies done in Burundi and the Democratic Republic of Congo where the levels ranged between 1.3 and $2410 \mu \mathrm{g} / \mathrm{kg}$ [40] and Kenya where mean aflatoxin level was $52.9 \mu \mathrm{g} / \mathrm{kg}$ [41], Rwanda had the lowest aflatoxin contamination, from this study.

The European Union (EU) has set standard limits for any products for direct human consumption, which is $4 \mu \mathrm{g} / \mathrm{kg}$ and $10 \mu \mathrm{g} / \mathrm{kg}$ for corn subjected to sorting and treatment before human consumption. The USA have specified the maximum acceptable limit for total aflatoxin at $20 \mu \mathrm{g} / \mathrm{kg}$. Kenya adopted a maximum limit allowed level of $10 \mu \mathrm{g} / \mathrm{kg}$ [42]. Rwanda adopted similar regulations for aflatoxins as Kenya $(10 \mu \mathrm{g} / \mathrm{kg})($ Rwanda Standards Bureau, not yet public). The distribution of aflatoxin contamination levels was done according to the EU standard, Kenyan and Rwanda regulations standards, and US regulation standards to compare the prevalence of aflatoxin in districts surveyed (Figure $6)$.

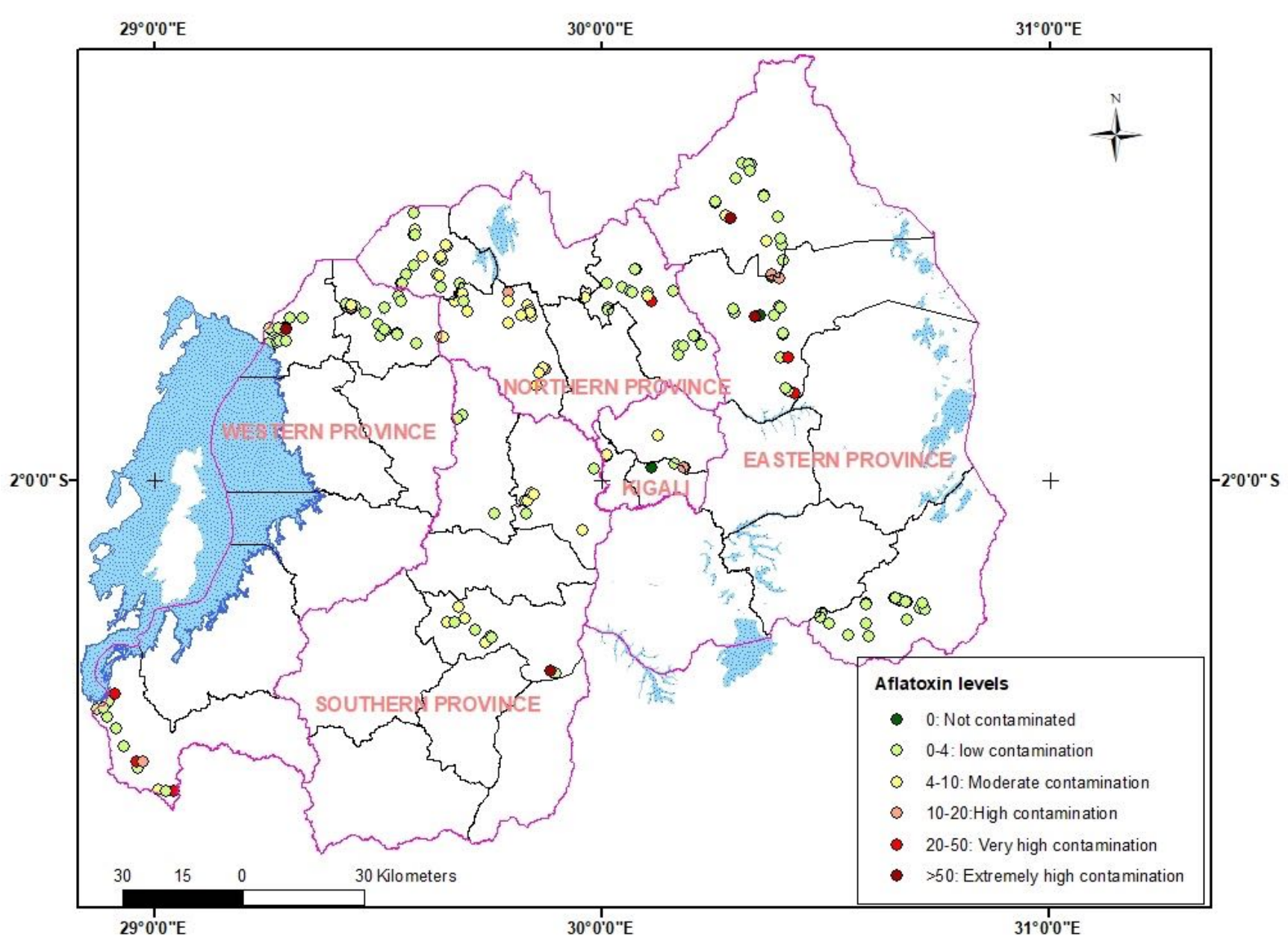

Figure 6: Mapping of aflatoxin levels in Districts surveyed 


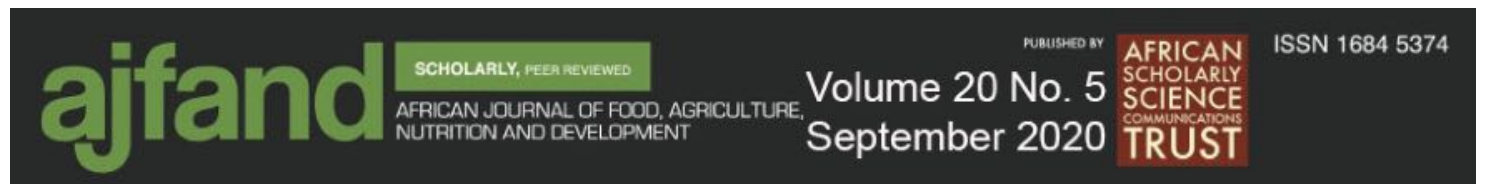

Many of the maize samples (90. $4 \%$ ) had aflatoxin levels below the limit of $10 \mu \mathrm{g} / \mathrm{kg}$ regulated in East Africa. About 9.6\% (22 samples) of these samples contained aflatoxins above the EU and Kenyan regulations standard limit, with 5.7\% (13 samples) above the US standards.

The household, the market and stores samples where had the aflatoxin levels of $>10$ were $7 \%, 18 \%$ and $5 \%$, respectively (Figure 7). More effort for aflatoxin mitigation is needed at the market level.

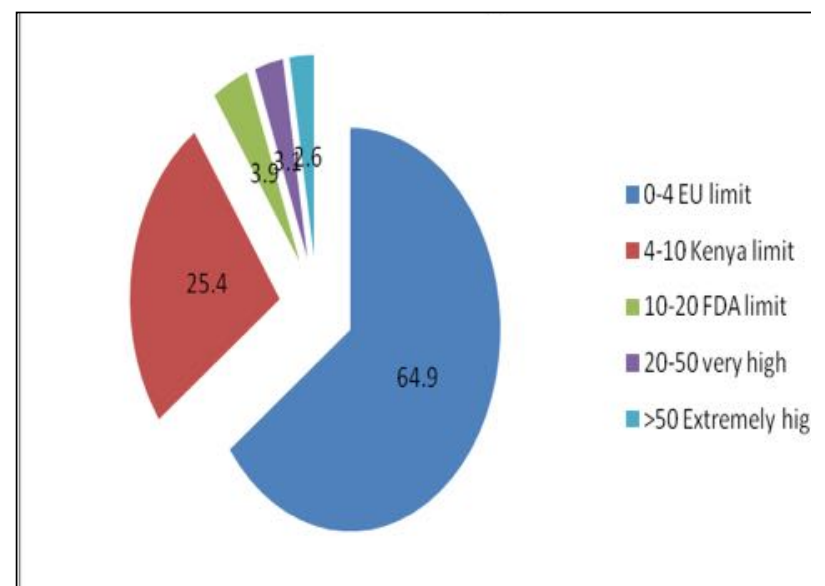

Aflatoxin levels in maize

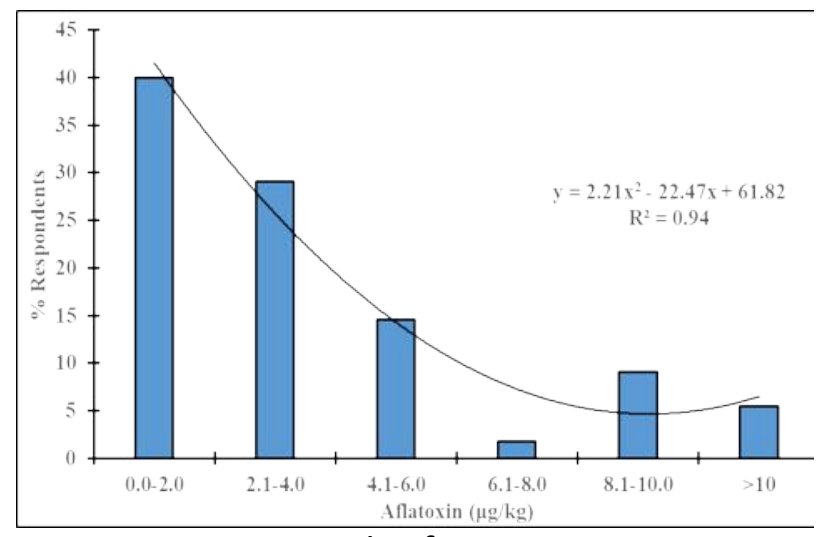

Samples from stores

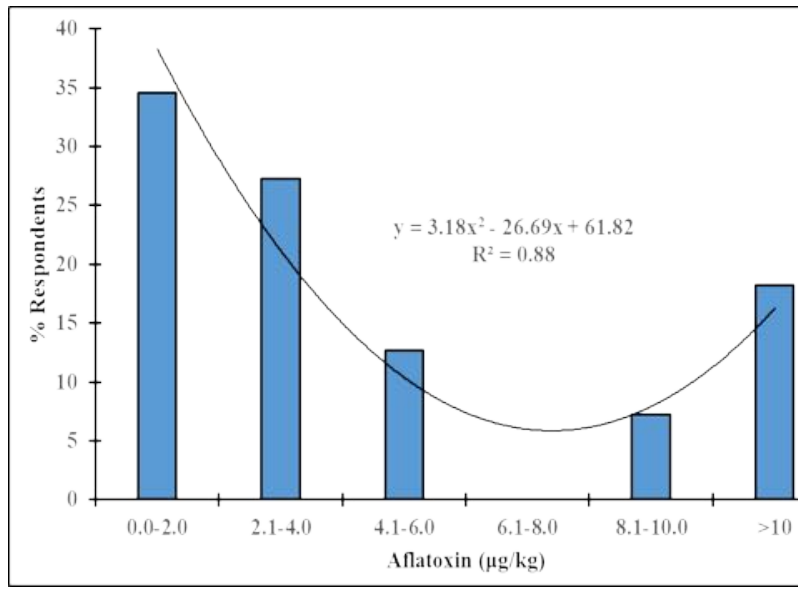

Samples from market

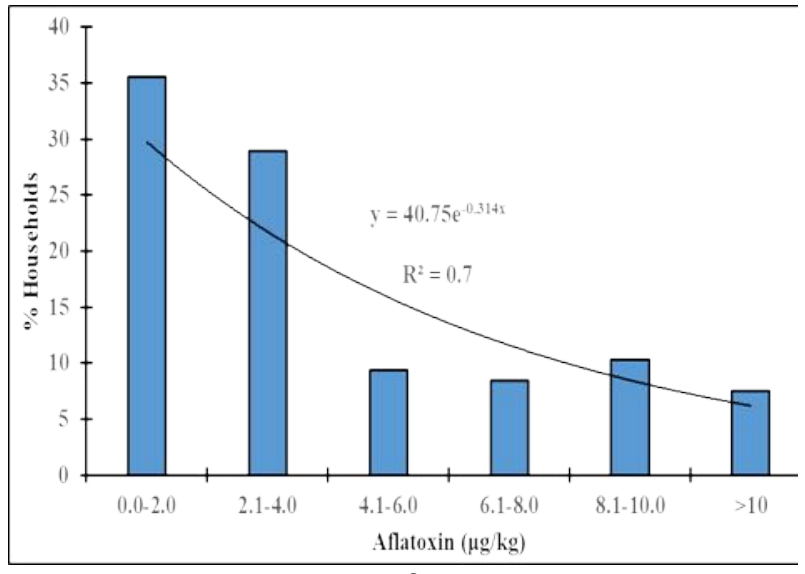

Samples from household

\section{Figure 7: General Aflatoxin levels distribution}

The postharvest handling value chain of cereals in Rwanda complies with the different steps, namely household corn handling, cobs or grain market, short term storage, Warehouse and final processing. At all different steps the mycotoxin contamination may occur. The research conducted by Williams et al. [43] about aflatoxin contamination in various African countries showed contamination level in market stored maize to be 158 $\mu \mathrm{g} / \mathrm{kg}$ in Tanzania, $120 \mu \mathrm{g} / \mathrm{kg}$ in Benin, with the highest contamination in Ghana at 490 $\mu \mathrm{g} / \mathrm{kg}$. The significance of contamination's increment depended on the level of awareness [43]. The findings in this study showed an aflatoxin contamination level of $100.9 \mu \mathrm{g} / \mathrm{kg}$ which is lower compared to the levels of discussed countries and Kenya, 


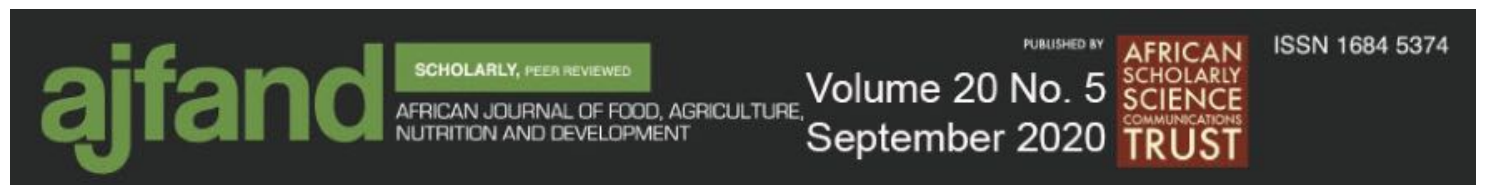

which can reach around $700 \mu \mathrm{g} / \mathrm{kg}$ [42]. The research conducted by Hell et al. [44] and James et al. [44] revealed that awareness plays an important role, but access to postharvest infrastructures contributes much in the mitigation of aflatoxin [44]. At this point, the findings of aflatoxin in maize at household level in Rwanda would depend on parameters like awareness and infrastructures as both are at the stage of development.

One sample at the market level and another one at processing stages had aflatoxin levels of $100 \mu \mathrm{g} / \mathrm{kg}$. The long time period of postharvest handling from harvesting to stage and processing level, would be the main cause. Further study with enough samples at the processing level is needed to draw conclusions. The corn goes along with different value chains and exacerbates the level of contamination. The research conducted by Kenya Bureau of Standards [41] showed that the corn is being sold from the household's small market to the processors and the long chain may increase the levels of contamination.

\section{Effect of mechanical damage and moisture content on aflatoxin levels}

As mechanical damage of grains, moisture content of grains and the temperature of the house store increase, Aflatoxin levels also increase (Figure 8).
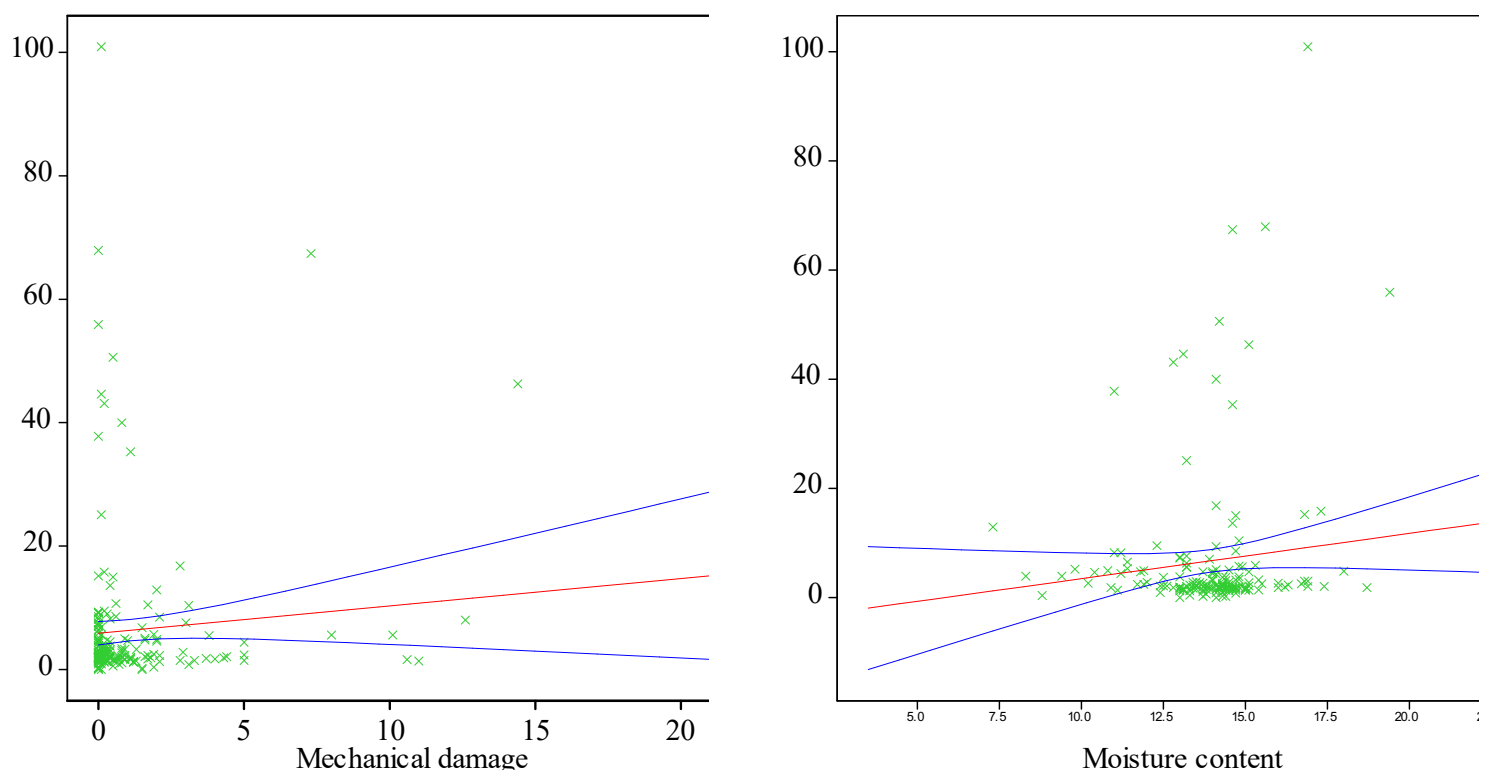

Figure 8: Maize mechanical damage and moisture content vs Aflatoxin levels

This is consistent with previous studies promoting post-harvest interventions that reduce mycotoxins contamination namely, rapid and proper drying, cleaning, sorting, postharvest insect and rodent control, and the use of pesticides and good storage facilities [44]. However, drying methods, storage facility composition (wall, roof, and floor), packaging materials, sorting, ventilation of the store house, storage conditions and source of maize did not influence the level of aflatoxin in maize. The difference between Districts under PASP intervention and those which did not benefit was not significant. Furthermore, no relationship was found between aflatoxin levels and socio characteristics studied (sex, age, level of education). 


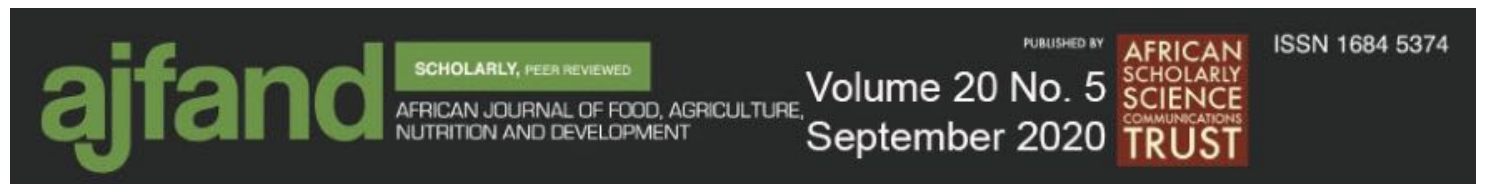

\section{Fumonisin contamination levels in maize}

In this study, samples were collected in 15 districts and the concentration of total fumonisin was analyzed (Table 5). The contamination mean values of fumonisin ranged from 0.06 (Kicukiro district) to $0.27 \mathrm{ppm}$ (Nyabihu district). Fumonisins are major mycotoxins found in maize and maize products. Fumonisins have been associated with human esophageal cancer in different countries such as China, South Africa, and others [44]. Because of their toxicity for both human and animals, different organizations set regulations to fix the maximum fumonisin content allowed in foods and feeds [45]. Levels of fuminisins in all samples, except one, did not reach the maximum levels set by the US Food and Drugs Administration in the USA $(2 \mu \mathrm{g} / \mathrm{g})$ and levels set by the European Union and Kenya for food intended for direct human consumption $(1 \mu \mathrm{g} / \mathrm{g})$ [42]. This shows that the levels of fumonisins in different districts where this study was conducted are not harmful to humans.

\section{Fumonisins by Cluster}

In this study, total fumonisins were analyzed by cluster and only one sample from the market showed a slightly higher level of fumonisins than the EU and US limit $2.3 \mu \mathrm{g} / \mathrm{g}$ (Table 6). The mean fumonisins contamination of maize samples was $0.14 \mu \mathrm{g} / \mathrm{g}, 0.12 \mu \mathrm{g} / \mathrm{g}$ and $0.19 \mu \mathrm{g} / \mathrm{g}$ for households, market and stores, respectively. The research findings did not show the significant difference between clusters of corn's value chain. Moreover, several researches concluded that the rate of contaminations would depend on environmental conditions [46]. Therefore, it is recommendable to correlate the corn's varieties and other environmental factors with occurrence of fumonisins.

\section{CONCLUSION}

This study indicates that most of the levels of aflatoxin in maize in Rwanda are below regulated standards. However, the $9.6 \%$ of aflatoxin contaminated samples above the East Africa regulated standards limit and levels above $20 \mu \mathrm{g} / \mathrm{kg}$ require more attention for preventive measures. The levels of fumonisins in maize found in this study were not harmful to humans. Most farmers need to be trained and made aware about aflatoxins and risk factors that contribute to mycotoxins contamination in food and feed. This permits farmers to prevent and control the aflatoxins for increased crops production especially maize, of good quality. The results would direct appropriate measures to recommend for control of mycotoxins in Rwanda and awareness creation.

More studies are needed for all susceptible commodities, on annual basis and in different seasons to constitute a database and evaluate the level of aflatoxin mitigation in Rwanda.

\section{ACKNOWLEDGEMENTS}

This project was funded by The Post-Harvest and Agribusiness Support Project (PASP), Rwanda. The support from Rwanda Agriculture and Animal Resources Development Board is highly appreciated. We are grateful to the National Technical Committee on Aflatoxin in Rwanda for the useful inputs to the manuscript. 


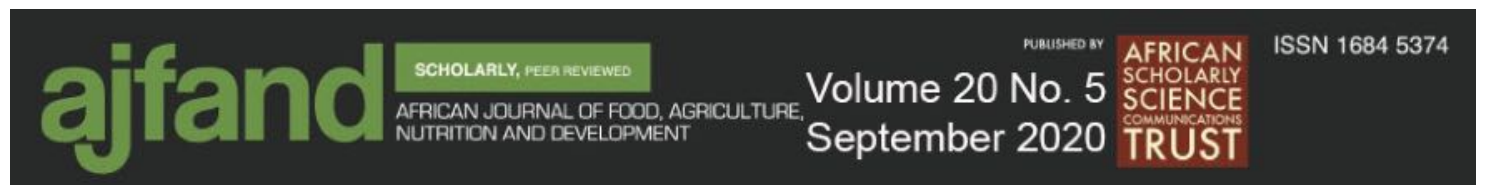

Table 1: Postharvest handling of maize

\begin{tabular}{lccccc}
\hline Variable & Mean & Minimum & Maximum & SD & SE \\
\hline Drying duration (days) & 26.71 & 2 & 40 & 3.4 & 2.8475 \\
Moisture content & 13.91 & 3.5 & 22.5 & 2.095 & 0.16 \\
Insect damage $(1 \mathrm{~kg})$ & 4.24 & 0 & 52.1 & 9.699 & 0.665 \\
Mechanical damage $(1 \mathrm{~kg})$ & 1.131 & 0 & 21.4 & 2.571 & 0.18 \\
Temperature $\left({ }^{\circ} \mathrm{C}\right)$ & 27.13 & 18.9 & 37 & 3.649 & 0.35 \\
Relative humidity & 21.95 & 1 & 68 & 17.256 & 2.174 \\
Days after harvesting & 90.13 & 1 & 390 & 72.76 & 6.19 \\
Storage duration (Days) & 43.33 & 1 & 240 & 55.1 & 4.97 \\
\hline
\end{tabular}


Table 2: Maize store materials

\begin{tabular}{|c|c|c|}
\hline Variable & Classifications & Total (\%) \\
\hline \multirow[t]{6}{*}{ Wall of store/house } & Bricks & 30.73 \\
\hline & Cement & 28.21 \\
\hline & Blocks & 8.72 \\
\hline & Mud & 9.63 \\
\hline & Bricks adobe & 21.79 \\
\hline & Iron sheet & 0.92 \\
\hline \multirow[t]{5}{*}{ Floor of store/house } & Tiles & 1.83 \\
\hline & Cement & 77.52 \\
\hline & Mud & 18.35 \\
\hline & Bricks & 1.83 \\
\hline & Stones & 0.46 \\
\hline \multirow[t]{3}{*}{ Roof } & Iron sheet & 87.44 \\
\hline & Grasses & 3.26 \\
\hline & Tiles & 9.30 \\
\hline
\end{tabular}




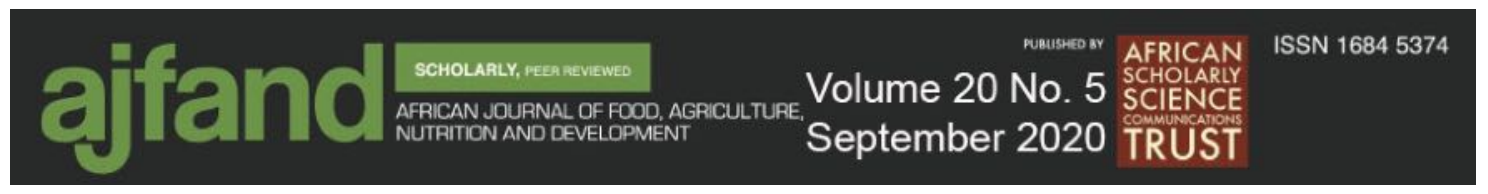

Table 3: Storage conditions

\begin{tabular}{|c|c|c|}
\hline Variable & Classification & Total \\
\hline \multirow[t]{5}{*}{ Days after harvesting } & Mean & 90.13 \\
\hline & Minimum & 1 \\
\hline & Maximum & 390 \\
\hline & SD & 72.76 \\
\hline & SE & 6.19 \\
\hline \multirow[t]{5}{*}{ Storage duration } & Mean & 43.33 \\
\hline & Minimum & 1 \\
\hline & maximum & 240 \\
\hline & $\mathrm{SD}$ & 55.10 \\
\hline & SE & 4.97 \\
\hline \multirow[t]{8}{*}{ Chemicals used in storage } & Aluminium phosphate & 1.30 \\
\hline & Cleoline & 0.87 \\
\hline & DDT & 3.91 \\
\hline & Fumigation tablets & 0.87 \\
\hline & Malathion & 5.22 \\
\hline & Rocket & 0.87 \\
\hline & Super scanner & 3.48 \\
\hline & No treatment & 83.48 \\
\hline \multirow[t]{2}{*}{ Leak roof } & Yes & 4.61 \\
\hline & No & 95.39 \\
\hline \multirow[t]{3}{*}{ Condition of store } & Excellent & 9.57 \\
\hline & Good & 41.15 \\
\hline & Poor & 49.28 \\
\hline \multirow[t]{2}{*}{ Presence of insects } & Yes & 43.19 \\
\hline & No & 56.81 \\
\hline \multirow[t]{2}{*}{ Ventilation } & Yes & 62.96 \\
\hline & No & 37.04 \\
\hline \multirow[t]{2}{*}{ Easy for Inspection } & Yes & 43.27 \\
\hline & No & 56.73 \\
\hline
\end{tabular}




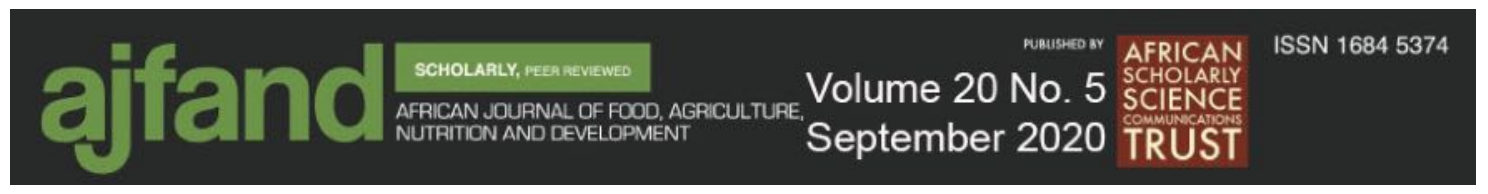

Table 4: Aflatoxin levels in maize by district

\begin{tabular}{|c|c|c|c|c|c|}
\hline \multirow[t]{2}{*}{ District } & \multicolumn{5}{|c|}{ Means aflatoxin level $(\mu \mathrm{g} / \mathrm{kg})$ by district } \\
\hline & $\mathbf{N}$ & Mean & SD & Minimum & Maximum \\
\hline Gakenke & 21 & 8.13 & 2.16 & 1.7 & 10.7 \\
\hline Gicumbi & 19 & 4.07 & 5.40 & 1.5 & 25.1 \\
\hline Musanze & 19 & 3.63 & 2.07 & 1.4 & 7.6 \\
\hline Kamonyi & 16 & 4.62 & 1.74 & 1.8 & 7.2 \\
\hline Muhanga & 5 & 2.07 & 1.26 & 0.36 & 3.9 \\
\hline Nyanza & 17 & 8.49 & 15.71 & 0.9 & 67.9 \\
\hline Gatsibo & 18 & 10.14 & 16.10 & 0 & 50.6 \\
\hline Kirehe & 20 & 1.36 & 0.53 & 0.22 & 2.1 \\
\hline Nyagatare & 19 & 8.38 & 17.10 & 0.19 & 67.4 \\
\hline Nyabihu & 20 & 4.68 & 12.07 & 1.2 & 55.9 \\
\hline Rubavu & 22 & 8.44 & 20.85 & 1.4 & 100.1 \\
\hline Rusizi & 20 & 13.75 & 24.75 & 1.7 & 100.9 \\
\hline Gasabo & 2 & 8.45 & - & 3.3 & 13.6 \\
\hline Kicukiro & 3 & 2.37 & - & 0 & 4.5 \\
\hline Nyarugenge & 6 & 4.00 & 0.82 & 2.9 & 5.2 \\
\hline Total & 227 & 6.69 & 13.43 & 0 & 100.9 \\
\hline
\end{tabular}




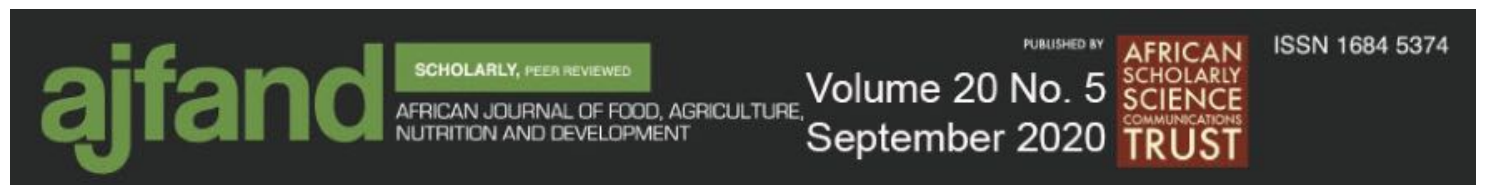

Table 5: Fumonisin level in maize by district

\begin{tabular}{|c|c|c|c|c|}
\hline \multirow[t]{2}{*}{ District } & \multicolumn{4}{|c|}{ Means fumonisin $(\mu \mathrm{g} / \mathrm{g})$ level by District } \\
\hline & $\mathrm{N}$ & Mean & Minimum & Maximum \\
\hline Gakenke & 20 & 0.23 & 0.02 & 0.88 \\
\hline Gicumbi & 18 & 0.09 & 0.01 & 0.4 \\
\hline Musanze & 19 & 0.08 & 0.01 & 0.37 \\
\hline Kamonyi & 16 & 0.14 & 0.005 & 1 \\
\hline Muhanga & 5 & 0.11 & 0.08 & 0.21 \\
\hline Nyanza & 17 & 0.12 & 0.01 & 0.62 \\
\hline Gatsibo & 19 & 0.12 & 0.02 & 0.47 \\
\hline Kirehe & 20 & 0.11 & 0.05 & 0.33 \\
\hline Nyagatare & 20 & 0.17 & 0.02 & 1.1 \\
\hline Nyabihu & 20 & 0.27 & 0.01 & 2.3 \\
\hline Rubavu & 22 & 0.16 & 0.02 & 1.2 \\
\hline Rusizi & 20 & 0.21 & 0.01 & 1 \\
\hline Gasabo & 2 & - & 0.03 & 0.1 \\
\hline Kicukiro & 3 & - & 0 & 0.12 \\
\hline Nyarugenge & 6 & 0.08 & 0.01 & 0.2 \\
\hline Total & 227 & 0.15 & 0 & 2.3 \\
\hline
\end{tabular}




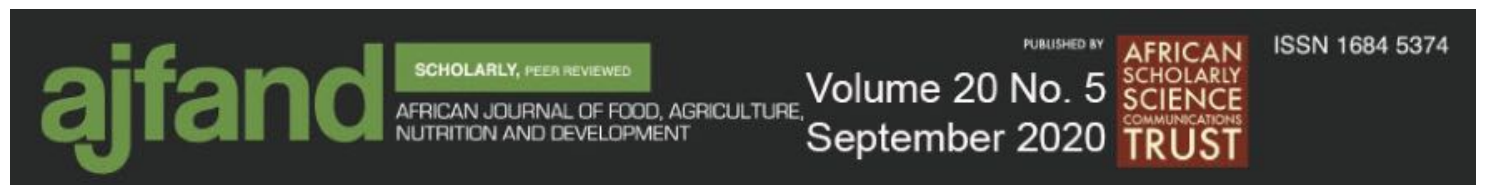

Table 6: Fumonisin levels in maize by Cluster

\begin{tabular}{lcccc}
\hline \multicolumn{5}{c}{ Means fumonisin $(\boldsymbol{\mu g} / \mathbf{g})$ by Cluster } \\
\hline Cluster & $\mathbf{N}$ & Mean & Minimum & Maximum \\
\hline Household & 105 & 0.14 & 0.007 & 1 \\
Market & 56 & 0.12 & 0 & 2.3 \\
Store & 58 & 0.19 & 0.01 & 1.3 \\
\hline
\end{tabular}




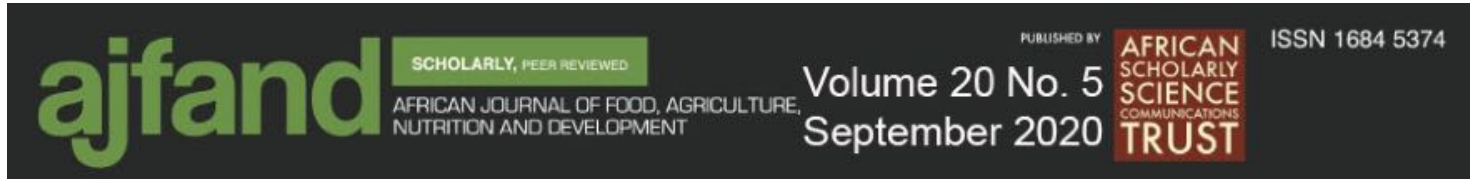

\section{REFERENCES}

1. National Institute of Statistics of Rwanda (NISR). Rwanda Statistical Year Book, 2018. https://www.statistics.gov.rw/publication/statistical-yearbook-2018. Accessed on February 01, 2019

2. National Institute of Statistics of Rwanda (NISR). Agricultural Household Survey report, 2018. https://www.statistics.gov.rw/publication/agriculturalhousehold-survey-2017. Accessed on January 01, 2019

3. National Institute of Statistics of Rwanda (NISR). Seasonal Agricultural Survey annual report, 2019. http://statistics.gov.rw/datasource/seasonal-agriculturalsurvey-2019. Accessed on January 01, 2019

4. Armachius $\mathbf{J}$ and $\mathbf{V}$ Zikankuba Mycotoxins contamination in maize alarms food safety in sub-Saharan Africa. Food Control, 2018; 90: 372-381.

5. Kebede $\mathbf{H}$, Liub $\mathbf{X}$, Jina $\mathbf{J}$ and $\mathbf{F}$ Xinga Current status of major mycotoxins contamination in food and feed in Africa. Food Control, 2020; 110: 106975.

6. Milani $\mathbf{J}$ M Ecological conditions affecting mycotoxin production in cereals: A review. Veterinarni Medicina, 2013; 58 (8): 405-411.

7. Bhatnagar D, Cary JW, Ehrlich $\mathbf{J}, \mathbf{Y u} \mathbf{J}$ and $\mathbf{T E}$ Cleveland Understanding the genetics of regulation of aflatoxin production and Aspergillus flavus development. Mycopathologia, 2006; 162: 155-166.

8. Niyibituronsa M, Onyango AN, Gaidashova S, Imathiu S, Uwizerwa M, Wanjuki I, Nganga F, Muhutu JC, Birungi J, Ghimire S, Raes K, De Boevre $\mathbf{M}$, De Saeger $\mathbf{S}$ and $\mathbf{J}$ Harvey Evaluation of mycotoxin content in soybean (Glycine max L.) grown in Rwanda. African Journal of Food, Agriculture, Nutrition and Development, 2018; 18(3): 13808-13824. DOI: 10.18697/ajfand.83.17710

9. Wild CP and YY Gong Mycotoxins and human disease: A largely ignored global health issue. Carcinogenesis, 2010; 31(1): 71-82.

10. Kachapulula PW, Akello J, Bandyopadhyay $\mathbf{R}$ and PJ Cotty Aflatoxin contamination of groundnut and maize in Zambia: Observed and potential concentrations. Journal of Applied Microbiology, 2017; 122(6): 1471 - 1482. https://doi.org/10.1111/jam.13448

11. Bankole $\mathbf{S}$, Schollenberger $\mathbf{M}$ and $\mathbf{W}$ Drochner Mycotoxins in food systems in sub-Saharan Africa: A review. Mycotoxin Research, 2006; 22(3): 163 - 169.

12. Wild CP, Miller JD and JD Groopman Mycotoxin control in low and middle income countries. IARC/WHO France, 2015; 9: 1-66. 


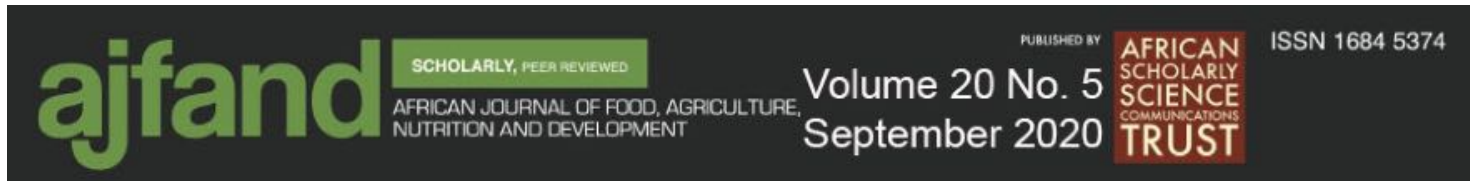

13. Nishimwe k, Wanjuki I, Karangwa $\mathbf{C}$, Darnell $\mathbf{R}$ and $\mathbf{J}$ Harvey An initial characterization of aflatoxin B1 contamination of maize sold in the principal retail markets of Kigali, Rwanda, Food control, 2017; 73: 574-580. https://doi.org/10.1016/j.foodcont.2016.09.006

14. Magembe K S, Mwatawala $M$ W, Mamiro D $\mathbf{P}$ and $\mathbf{E} \mathbf{E}$ Chingonikaya Assessment of awareness of mycotoxins infections in stored maize (Zea mays L.) and groundnut (arachis hypogea L.) in Kilosa District, Tanzania. International Journal of Food Contamination, 2016; 3:12.

15. Umereweneza D, Kamizikunze $\mathbf{T}$ and $\mathbf{T}$ Muhizi 2018. Assessment of mycotoxins types in some foodstuff consumed in Rwanda. Food Control, 2018; 85: 432-436.

16. Whitaker TB Sampling foods for mycotoxins. Food Addit.Contam. 2006; 23(1):50-61.

17. Neogen Corporation. Reveal $\mathrm{Q}^{+}$for aflatoxin Quantitative Test, AccuScan Gold, 2017. http://www.neogen.com/corporate/patents.html. Accessed on February 01, 2019.

18. Neogen Corporation. Reveal $\mathrm{Q}^{+}$for fumonisin Quantitative Test, AccuScan Gold, 2017. http://www.neogen.com/corporate/patents.html. Accessed on February 01, 2019.

19. Johnson AM, Fulton1 JR, Abdoulaye T, Ayedun B, Widmar NJO, Akande A, Bandyopadhyay $\mathbf{R}$ and $\mathbf{V}$ Manyong Aflatoxin awareness and Aflasafe adoption potential of Nigerian Smallholder maize farmers. World Mycotoxin Journal, 2018 online, Wagenigen Academic Publisher. DOI: 10.3920/WMJ2018.2345

20. Sahil VP, Tejas CB, Hiren NB, Pratibha S and K Abhay Aflatoxins: Causes \& Effects. AGROBIOS, 2015; 13(9): 140-148.

21. Pamela A and D Malunda Analysis of Three Rwanda Strategic Agricultural Policies and Programmes (Vision 2020, EDPRS., PSTA) with a Critical Gender Informed Review of their Implementation and Financing, 2014: 1111-1134.

22. Alemayehu M, Beuving $\mathbf{J}$ and $\mathbf{R}$ Ruben Risk aversion, cooperative membership, and path dependences of smallholder farmers in Ethiopia. Review of Development Economics, 2020; 24 (1): 167-187.

23. USAID. Post-harvest Handling and Storage (PHHS). 2012 https://www.researchgate.net/publication/216366045_Agricultural postharvest_Innovative technologies_and access to niche market_Experience_fro m Gataraga IP Rwanda. Accessed on December 17, 2019. 
24. Mbuge DO, Negrini R, Nyakundi LO, Kuate SP, Bandyopadhyay R, Muiru

WM and R Mezzenga Application of superabsorbent polymers (SAP) as desiccants to dry maize and reduce aflatoxin contamination. Journal of Food Science and Technology, 2016; 53(8): 3157-3165.

https://doi.org/10.1007/s13197-016-2289-6

25. Mutungi C, Muthoni F, Bekunda M, Audifas G, Kabula E and A Adebayo Physical quality of maize grain harvested and stored by smallholder farmers in the Northern highlands of Tanzania: Effects of harvesting and pre-storage handling practices in two marginally contrasting agro-locations. Journal of Stored Products Research, 2019; 84: 101517.

26. Kumar D and P Kalita Reducing Postharvest losses during storage of grain crops to strengther food security in developing countries: Published online 2017 Jan 15. doi: 10.3390/foods6010008. https://www.ncbi.nlm.nih.gov/pmc/articles/PMC5296677/

27. Weinberg Z, Yan Y, Chen Y and F Smcha The effect of moisture level on highmoisture maize (Zea mays L.) under hermetic storage conditions - in vitro studies: Journal of Stored Products Research 2008; 44(2):136-144.

28. Nyamulinda B, Bizoza A and C Wanjiku Agricultural post-harvest Innovative technologies and access to niche market: Experience from Gataraga IP, Rwanda: Learning Publics. Journal of Agriculture and Environmental Studies, 2011; 2 (1): $1-23$

29. Kiaya V Post-Harvest Losses and Strategies to Reduce Them; Technical paper and Scientific \& Technical Department: ACF,2014.

https://www.actioncontrelafaim.org/wp-

content/uploads/2018/01/technical_paper_phl_.pdf. Accessed on December 17, 2019.

30. Kitinoja L, Sunil S, Susanta KR and AA Kader Postharvest technology for developing countries: challenges and opportunities in research, outreach and advocacy: Journal of the science of food and agriculture. JSFA, 2011; 91(4): 597603 https://doi.org/10.1002/jsfa.4295

31. Mrema GC, Gumbe LO, Chepete HJ and JO Agullo "Grain Crop Drying, Handling and Storage." In Rural Structures in the Tropics: Design and Development. Rome, Italy: FAO, 2011; 363-411 http://www.fao.org/3/i2433e/i2433e10.pdf. Accessed on December 17, 2019.

32. Zambrano MV, Dutta B, Mercer DG, Heather L, MacLean HL and MF Touchie Assessment of moisture content measurement methods of dried food products in small-scale operations in developing countries: A review 2019; 88: 484-496 https://www.sciencedirect.com/science/article/pii/S0924224418304898 Accessed on December 17, 2019 


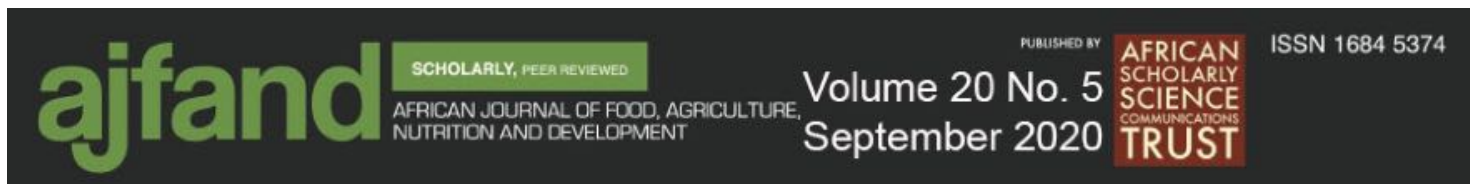

33. Hodges $\mathbf{R}$ and $\mathbf{T}$ Stathers Training Manual for improving grain post harvest handling and storage: University of Greenwich Natural resources institute, UN world Food Program, 2012. https://documents.wfp.org/stellent/groups/public/documents/reports/wfp250916.p df. Accessed onDecember 17, 2019.

34. Probst C, Schulthess F and PJ Cotty Impact of Aspergillus section Flavi community structure on the development of lethal levels of aflatoxins in Kenyan maize (Zea mays). Journal of Applied Microbiology, 2010; 108(2): 600-610.

35. Ariño A, Herrera M, Estopañan G, Rota MC, Carramiñana JJ, Juan T and A Herrera Aflatoxins in bulk and pre-packed pistachios sold in Spain and effect of roasting. Food Control, 2009; 20(9): 811-814.

36. Chulze SN Strategies to reduce mycotoxin levels in maize during storage: a review. Food Addit Contam Part A Chem Anal Control Expo Risk Assess, 2010; 27(5):651-7. doi: 10.1080/19440040903573032

37. Lagogianni C and D Tsitsigiannis Effective chemical management for prevention of aflatoxins in maize. Phytopathologia Mediterranea, 2018; 57(1): 186-197.

38. Sumner $\mathbf{P} \mathbf{E}$ and RD Lee Reducing aflatoxin in corn during harvest and storage. UGA Cooperative Extension Bulletin 1231, 2009.

https://secure.caes.uga.edu/extension/publications/files/pdf/B\%201231 4.PDF. Accessed on December 17, 2019.

39. Befikadu D Factors Affecting Quality of Grain Stored in Ethiopian Traditional Storage Structures and Opportunities for Improvement. International Journal of Sciences: Basic and Applied Research, 2014; 18(1): 235-257.

40. Udomkun P, Mutegi C, Wossen T, Atehnkeng J, sharwasi LN, Njukwe E, Vanlauwe $\mathbf{V}$ and $\mathbf{R}$ Bandyopadhyay Occurrence of aflatoxin in agricultural produce fromlocal markets in Burundi and Eastern Democratic Republic of Congo. Food Sci Nutr. 2018; 00:1-12. https://doi.org/10.1002/fsn3.787

41. Lewis L, Onsongo M, Njapau H, Schurz-Rogers H, Luber G, Kieszak S, Nyamongo J, Backer L, Dahiye AM, Misore A, DeCock K, Rubin C and The Kenya Aflatoxicosis Investigation Group Aflatoxin Contamination of Commercial Maize Products during an Outbreak of Acute Aflatoxicosis in Eastern and Central Kenya. Environmental Health Perspectives, 2005; 113(12): 17631767.

42. Mutiga SK, Hoffmann V, Harvey JW, Milgroom MG and RJ Nelson Assessment of aflatoxin and fumonisin contamination of maize in western Kenya Phytopathology, 2015; 105: xx-xx. DOI: 10.1094/PHYTO-10-14-0269-R 


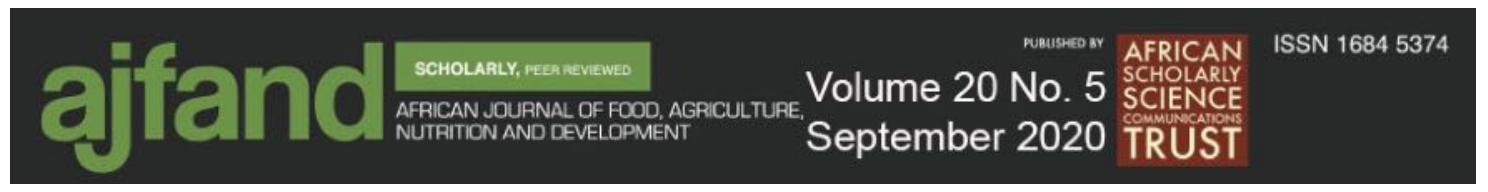

43. Williams JH, Phillips TD, Jolly PE, Stiles JK, Jolly CM and D Aggarwal Human aflatoxicosis in developing countries: a review of toxicology, exposure, potential health consequences, and interventions. Am J Clin Nutr, 2004;80:110622.

44. James B, Adda C, Cardwell K, Annang D, Hell K and S Korie Public information campaign on aflatoxin contamination of maize grains in market stores in Benin, Ghana, and Togo. Food Addit Contam. 2007; 24:1283-1291.

45. Ncube E, Flett BC, Waalwijk $\mathbf{C}$ and A Viljoen Fusarium spp. and levels of fumonisins in maize produced by subsistence farmers in South Africa. S Afr J Sci. 2011; 107(1/2): 1-7. Doi: http://dx.doi.org/10.4102/sajs.v107i1/2.367

46. Cecile LG, Sylvaine B, Didier K, and JD Bailly Assessing Risk of Fumonisin Contamination in Maize Using Near-Infrared Spectroscopy. Journal of Chemistry, 2015; 2015 (485864): 1-10. http://dx.doi.org/10.1155/2015/485864. 